\title{
Experimental Study on Ultrasonic Shot Peening Forming and Surface Properties of AALY12
}

\author{
Shi-hong Lu, Chao-xun Liu, Yi-feng Zhu
}

\begin{abstract}
Ultrasonic shot peening (USP) on AALY12 sheet was studied. Several parameters (arc heights, surface roughness, surface topography and micro hardness) with different USP process parameters were measured. The research proposes that radius of curvature of shot peened sheet increases with time and electric current decreasing, while increases with pin diameter increasing, and radius of curvature reaches a saturation level after a specific processing time and electric current. An empirical model of the relationship between radius of curvature and pin diameter, electric current, time was also obtained. The research shows that the increment of surface and vertical micro hardness of material is more obvious with longer time and higher value of electric current, which can be up to $20 \%$ and $28 \%$ respectively.
\end{abstract}

Keywords - USP forming, surface properties, radius of curvature, residual stress.

\section{INTRODUCTION}

$\mathrm{U}$ LTRASONIC shot peening is one of die less sheet metal forming and a mechanical surface treatment proposed in recent years, which aims at inducing strong and multi-directional impacts on the surface of materials with spherical shots or pins accelerated by high-power ultrasounds in a short time. Nowadays, USP is widely employed to enhance the stiffness, strength and fatigue life of mechanical components [1], [2]. And USP has wider application prospects in aerospace, automotive and other industrial fields, which is of theoretical and practical significance.

Currently, research on USP forming technology of metal sheet is not enough, but many studies have been conducted over the years to study the USP mechanism and surface modification of USP. V.O. Abramov [3] investigated on the drive phase, impact behavior and rebound behavior of shots in the process. A.Sanda [4] made systematic research on the affection of process parameters, B. N. Mordyuk [5] studied on the surface properties of USP metal sheet.

\section{II.TEST CONDITIONS}

\section{A. Test Equipment and Materials}

Deburred work samples of AALY12 were cut from experimental plate with its dimension of $150 \times 35 \times 1.5 \mathrm{~mm}$. The

Shi-hong $\mathrm{Lu}$ is with the Nanjing University of Aeronautics \& Astronautics, Nanjing 210000 China (phone: +8613951807635; e-mail: lush@nuaa.edu.cn).

Chao-xun Liu is with the Nanjing University of Aeronautics \& Astronautics, Nanjing 210000 China (phone: +8618262636568; e-mail: 498874887@qq.com).

Yi-feng Zhu is with the Nanjing University of Aeronautics \& Astronautics, Nanjing 210000 China (phone: +8615195943300; e-mail: zhuyifeng@nuaa. edu.cn).
USP device used in this experiment is self-developed by Nanjing University of Aeronautics and Astronautics (Shown in Fig. 1), and the diameters of pins armed in the chamber are $2 \mathrm{~mm}, 3 \mathrm{~mm}$ and $5 \mathrm{~mm}$. As to this device, its maximum power is $800 \mathrm{~W}$, and the horn vibration frequency is $20 \mathrm{KHz}$ with $50 \mu \mathrm{m}$ amplitude adjusted by operating electric current of ultrasonic creators, which could be up to the top value of 2.5A .TR101 pocket surface roughness tester, DM2000 optical microscope and MVC-1000A1 were used to measure or observe the surface roughness, surface morphology and the sample hardness.

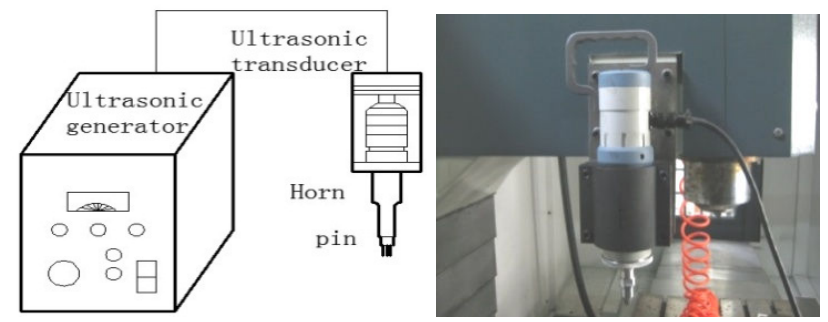

Fig. 1 USP device schematic and device clamp on the CNC machine

\section{B. Test Method}

To ensure free deformation in Z-direction (Spindle direction of CNC machine) during the process, the top surface of samples should be in free state, while the upright surfaces of samples should be fixed. By changing time (3min, 5min, $10 \mathrm{~min}$, $15 \mathrm{~min})$, electric current $(1.0-2.5 \mathrm{~A})$ and pin diameter $(2 \mathrm{~mm}$, $3 \mathrm{~mm}, 5 \mathrm{~mm})$, the experiment was carried out to obtain the influence of USP process on the radius of curvature and surface properties after the treatment.

\section{EXPERIMENTAL RESULTS AND DISCUSSION}

\section{A. USP Parameters Effect on the Sheet Bending}

Measure the sheet arc high-value with USP forming and use the following formula to calculation the radius of curvature,

$$
R=\frac{A^{2}+4 H^{2}}{8 H}
$$

where $\mathrm{R}$ is the radius of curvature, $\mathrm{H}$ is the arc high-value, $\mathrm{A}$ is measurement span.

Fig. 2 shows the relationship between the radius of curvature and USP parameters. The results show that radius of curvature increases with electric current decreasing. When electric current is relatively small, the radius of curvature decreases significantly with electric current increasing; once electric current arrives at $2.0 \mathrm{~A}$, the decreasing rate of radius becomes smaller. When time is relatively short, the radius of curvature 
decreases with time increasing, once time increasing up to $10 \mathrm{~min}$, radius of curvature reaches a saturation level, the decreasing rate of the radius of curvature becomes smaller. Radius of curvature increases with diameter of pin increasing within 5min. However, as time increases, the trend is weakened.

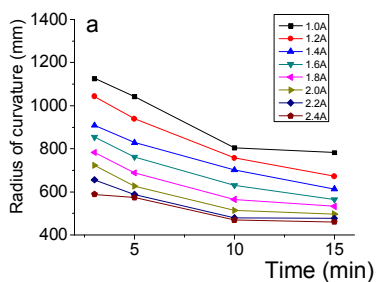

(a) $2 \mathrm{~mm}$, time and electric current

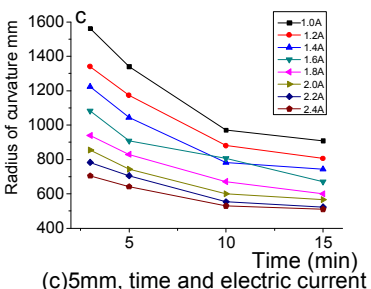

(c) $5 \mathrm{~mm}$, time and electric curren

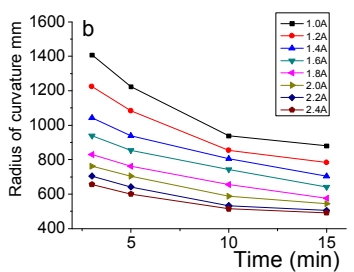

(b) $3 \mathrm{~mm}$, time and electric curren

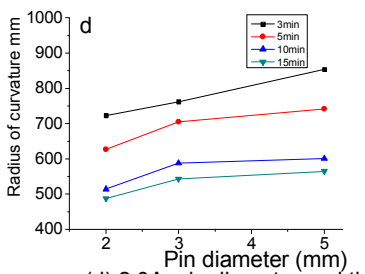

(d) 2.0A, pin diameter and time
Fig. 2 The relationship between radius of curvature and USP parameters

Explanation above shows that time has the most significant influence on USP forming, followed by electric current and pin diameter. An empirical model describing the relationship between radius of curvature and pin diameter, electric current, time can be obtained using curve fitting method.

$$
\mathrm{Y}=1466.9+46.5 \mathrm{~d}-370.2 \mathrm{I}-26.4 \mathrm{t}
$$

where $\mathrm{Y}$ is radius of curvature, $\mathrm{d}$ is pin diameter, $\mathrm{I}$ is electric current, It is time.

\section{B. USP Effect on the Surface Properties}

Fig. 3 shows the surface morphology without and with USP. It can be seen from Fig. 3 (a), there are many processing texture on base material surface, which is mainly produced during the rolling process. With USP treatment, the sample surface is significantly furrowed in Figs. 3 (b)-(d). These furrows are due to the dragging of the tool tip on the surface during USP, and the furrow size increases with pin diameter increase. Among ones with USP, the one with $2 \mathrm{~mm}$ pin is the smoothest.

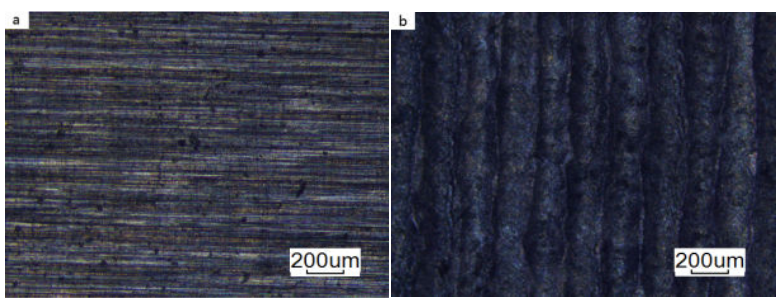

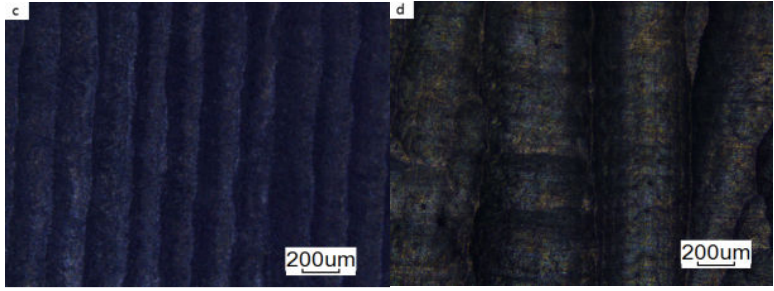

Fig. 3 The relationship between surface morphology and pin diameter (a): base material, (b): $2 \mathrm{~mm}$ pin, (c): $3 \mathrm{~mm}$ pin, (d): $5 \mathrm{~mm}$ pin)

It can be seen from Fig. 4, surface roughness increases with electric current increase, for the higher current, the higher velocity and force of pin impact on the sheet surface. Surface roughness increases with time increase, but when time arrives at $10 \mathrm{~min}$, the roughness is declining. Roughness increases almost linearly with pin diameter increase. Besides, it is obvious that the $2 \mathrm{~mm}$ pin makes the best surface roughness.

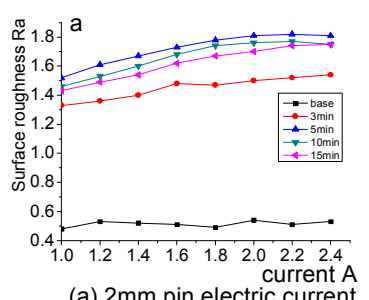

(a) $2 \mathrm{~mm}$ pin,electric current

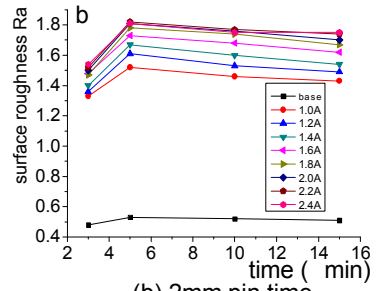

(b) $2 \mathrm{~mm}$ pin,time

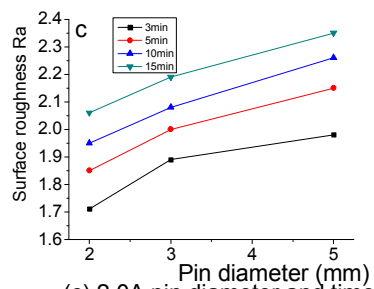

(c) $2.0 \mathrm{~A}$, pin diameter and time

Fig. 4 The relationship between surface roughness and USP parameters

Micro hardness of surface and cross-sectional is shown in Fig. 5, Surface micro hardness increases with electric current, time increase, micro hardness decreases gradually with pin diameter increase, but the change is quite small. In addition, micro hardness along cross-sectional increases firstly, and then turns back to base metal hardness. Compared to the base sample, its surface and along depth hardness were increased $20 \%, 28 \%$ respectively and the hardening depth (about $0.35 \mathrm{~mm}$ ) is higher than traditional shot peening (about $0.1 \mathrm{~mm}$ ) [6].

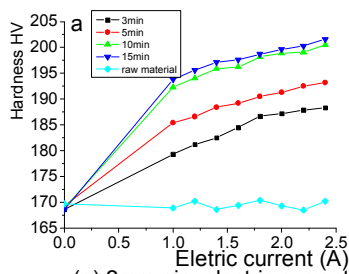

(a) $2 \mathrm{~mm}$ pin, electric curren

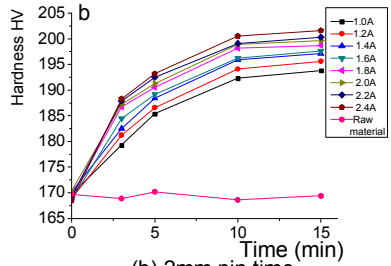

(b) $2 \mathrm{~mm}$ pin,time 


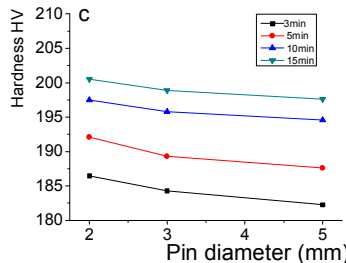

(c) 2.0A, pin diameter

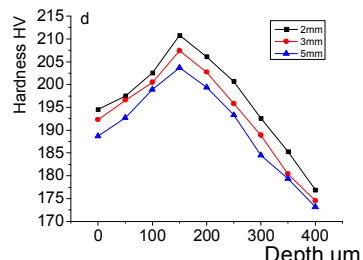

(d) $2.0 \mathrm{~A}, 10 \mathrm{~min}$, along the depth

Fig. 5 The relationship between micro hardness and USP parameters

Through the above analysis combined with the USP forming and surface properties, the USP optimum forming parameters are $2 \mathrm{~mm}$ pin diameter, $10 \mathrm{~min}$ USP treatment time, $1.6 \mathrm{~A}-2.0 \mathrm{~A}$ electric current.

\section{CONCLUSIONS}

(1) Time has the most significant influence on USP forming, followed by electric current and pin diameter has the least significant influence and optimum forming parameters are $2 \mathrm{~mm}$ pin diameter, $10 \mathrm{~min}$ treatment time, $1.6 \mathrm{~A}-2.0 \mathrm{~A}$ electric current.

(2) With USP treatment the sample surface is significantly furrowed, and the furrow size increases with pin diameter increase.

(3) Compared to the base sample, sample surface and along depth hardness were increased $20 \%, 28 \%$ respectively and the hardening depth (about $0.35 \mathrm{~mm}$ ) is higher than traditional shot peening (about $0.1 \mathrm{~mm}$ ) [6]

\section{ACKNOWLEDGMENT}

National natural science foundation, basic research of high energy and high strain ultrasonic shot peening forming of metal sheet, No. 51175257.

\section{REFERENCES}

[1] Gao lin. Research of high-energy USP technology in sheet metal forming [D]. Nanjing University of Aeronautics and Astronautics, 2012

[2] Liu Hai-ying. Research of the mechanism of Ultrasonic shot peening [D]. Taiyuan University of technology, 2008

[3] V.O. Abramova, O.V. Abramov. Surface hardening of metals by ultrasonically accelerated small metal balls [J]. Ultrasonics, Vol. 36(1998),p.1013-1019

[4] A. Sandá, V. García Navas, O. Gonzalo. Surface state of Inconel 718 ultrasonic shot peened: Effect of processing time,material and quantity of shot balls and distance from radiating surface to sample [J]. Materials and Design, Vol. 32(2011), p. 2213-2220

[5] Bohdan N. Mordyuk. Ultrasonic impact peening for the surface properties management [J]. Journal of Sound and Vibration, Vol. 308(2007), p. 855 $-866$

[6] Miao hong, Zuo Dun-wen. Effect of shot peening on surface properties of NAK80 steel [J]. Journal of Jilin University (Engineering Science), Vol.41 (2011), p.1290-1294 